\title{
A Study on Dynamic Amplification Factor and Structure Parameter of Bridge Deck Pavement Based on Bridge Deck Pavement Roughness
}

\author{
Fei Han (D), ${ }^{1}$ Dan-hui Dan $\mathbb{D}^{D},{ }^{1}$ and Hu Wang ${ }^{2}$ \\ ${ }^{1}$ Department of Bridge Engineering, Tongji University, Shanghai 200092, China \\ ${ }^{2}$ School of Science, Chang'an University, Xi'an, Shannxi 710064, China \\ Correspondence should be addressed to Fei Han; 674623368@qq.com
}

Received 6 November 2017; Revised 8 February 2018; Accepted 21 February 2018; Published 1 April 2018

Academic Editor: Yuqing Zhang

Copyright (C) 2018 Fei Han et al. This is an open access article distributed under the Creative Commons Attribution License, which permits unrestricted use, distribution, and reproduction in any medium, provided the original work is properly cited.

\begin{abstract}
In order to study the coupled influence of deck pavement roughness and velocity on dynamic amplification factor, a 2-DOF $1 / 4$ vehicle model is employed to establish the vehicle-bridge-coupled vibration system. The random dynamic load of running vehicle simulated by software MATLAB is applied on bridge deck pavement (BDP) through ANSYS software. Besides, the influence of BDP parameters on control stress under static load and random vibration load is analyzed. The results show that if the surface of BDP is smooth, the dynamic magnification coefficient would first increase and then decrease with increasing of vehicle velocity and reach its maximum value when $v=20 \mathrm{~m} / \mathrm{s}$; if the surface of BDP is rough, the maximal and minimum values of the dynamic amplification coefficient (DAC) occur, respectively, when the velocity reaches $10 \mathrm{~m} / \mathrm{s}$ and $15 \mathrm{~m} / \mathrm{s}$. For a composite bridge deck with the cushion layer, the thickness of asphalt pavement should be not too thick or thin and better to be controlled for about $10 \mathrm{~cm}$; with the increasing of cushion layer thickness, the control stress of deck pavement is all decreased and show similar change regularity under effect of different loads. In view of self-weight of structure, the thickness of the cushion layer is recommended to be controlled for about $4 \mathrm{~cm}$.
\end{abstract}

\section{Introduction}

The deck pavement of long-span bridges is usually susceptible to various destructions such as cracking, lamination, steel corrosion, and concrete degradation under vehicle loads. In the interaction of tire and bridge deck, the additional dynamic load will generate because of the roughness of BDPs. Therefore, the actual vehicle load applied on BDPs is of random load, the moving constant load cannot reflect the real dynamic behavior of BDPs. However, existing mechanical analysis of BDPs is concentrated on orthotropic plate pavement system under static vehicle load. Most literatures simplify the vehicle load as moving constant load when analyzing the dynamic behavior of BDPs, and the dynamic effect of vehicle load is considered using an empirical amplification factor.

Dynamic vehicle load will bring bridges a greater effect on structural stress and deformation compared with the static vehicle load, and this response amplification phenomenon of stress and deformation caused by vehicle dynamic load is called the impact effect [1]. Dynamic load of vehicle consists of vehicle body weight and additional dynamic load caused by surface roughness of BDPs; the specific value of dead and additional load is defined as the dynamic amplification factor (DAF). In most existing studies, the vehicle-bridge-coupled vibration is taken into consideration ignoring the effect of BDPs [2-4]. DAFs play a vital role in the practice of bridge design and condition assessment. Accurate evaluation of DAFs will lead to safe and economical designs for new bridges and provide valuable information for condition assessment and management of existing bridges. However, the evaluation of a DAF is a rather complicated issue because of the sophisticated mechanism of the vehicle-bridge interaction (VBI) and a large number of parameters influencing DAFs, including the dynamic characteristics of both the bridge and the vehicle, road surface condition, and vehicle speed, where the road surface condition and vehicle speed are two critical index affecting DAFs significantly and have been widely investigated [5-9]. Though comprehensive studies of 


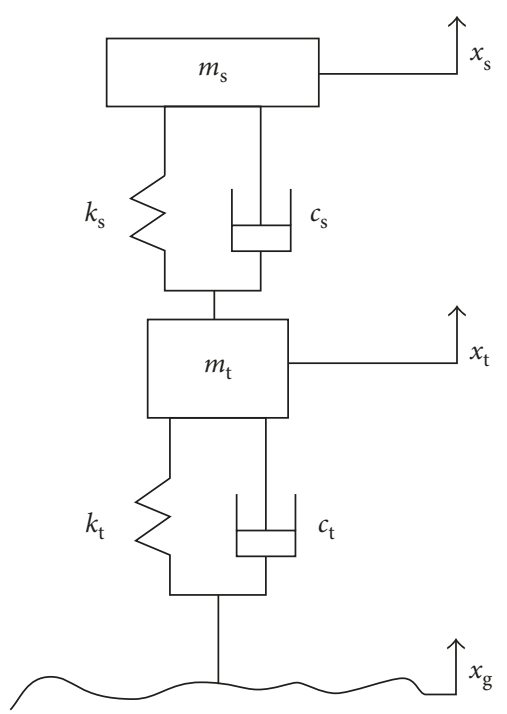

Figure 1: Single-wheel double-degree of freedom vehicle mode.

the DAF of highway bridges have been finished; due to the neglect of the influence of pavement layer, heavy maintenance cost of BDPs was paid during later maintenance and reinforce of the bridge. In China, BDPs were designed as an independent part isolated from the bridge girder, without considering the influence of deck pavement on structure [10]. However, BDPs are usually susceptible to cracking, lamination, steel corrosion, and concrete degradation, which accelerate the growth of damage; therefore, it is necessary to investigate the mechanical behavior of BDPs and analyze the effect of velocity and the roughness of BDPs on DAFs.

Existing researches have analyzed the dynamic response of BDPs under vehicle dynamic load considering road roughness and vehicle velocity [11], and the variation rule of vehicle load caused by structural parameters of bridge and vehicle speed has been investigated as well $[12,13]$. However, the effect of DAFs caused by the design parameter of BDPs has not been studied considering the effect of road roughness. Besides, the investigation of the relation between the roughness and DAF has not been considered yet. Based on this, in this paper, the vehicle random dynamic load has been first simulated by MATLAB based on International Roughness Index (IRI) to analyze the variation law of DAF under the effect of BDP roughness and velocity. Then, the vehicle random dynamic load is applied on the finite element model of a typical bridge to investigate the relation between design parameters of BDPs and pavement stress state.

\section{Dynamic Model of Vehicle Vibration}

The most typical vehicle vibration model used for pavement mechanics analysis is the 2-DOF single-wheel vehicle model [14]. As shown in Figure 1, the total mass of bodywork, spring, and suspension is denoted by $m_{\mathrm{s}} ; m_{\mathrm{t}}$ represents tire mass; $c_{\mathrm{s}}$ and $k_{\mathrm{s}}$ represent damping and stiffness of spring; and $c_{\mathrm{t}}$ and $k_{\mathrm{t}}$ represent the damping and stiffness of tires,

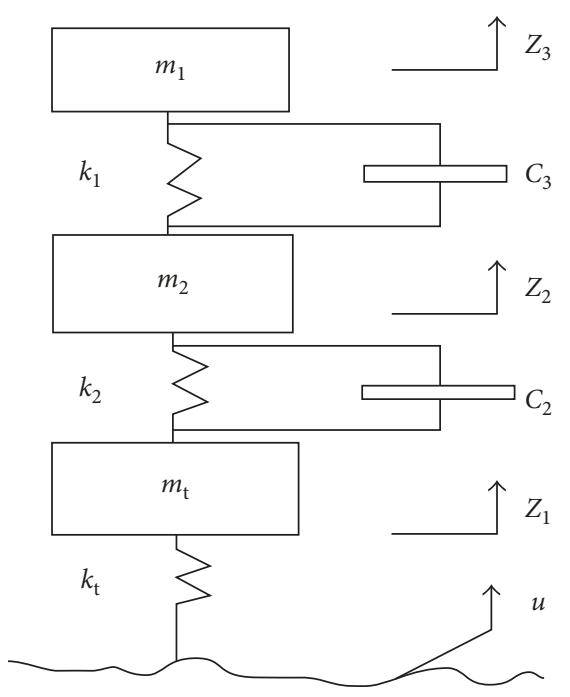

Figure 2: Three-mass vehicle mode.

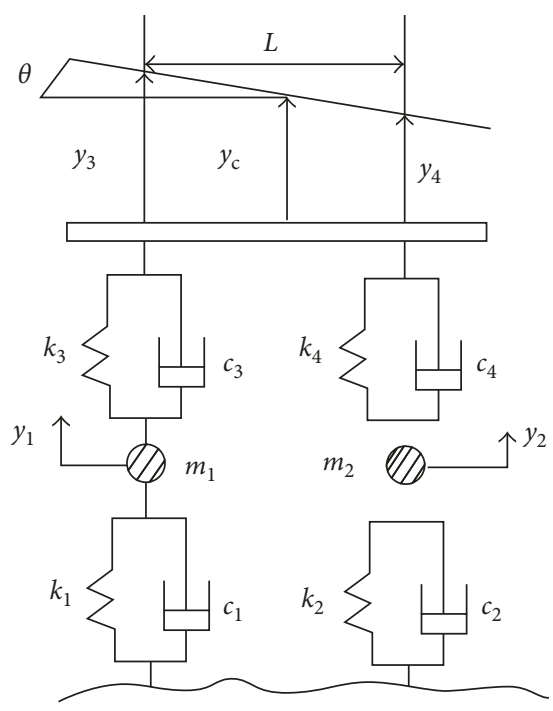

Figure 3: Four-degree of freedom vehicle model.

respectively. Other vehicle vibration models, such as 3-DOF single-wheel and 4-DOF vehicle vibration models, can be seen from Figures 2 and 3, respectively [15]. Though more complicated model such as biaxial 5-DOF and four-axle 10DOF vibration models $[16,17]$ are raised by relevant study, 2-DOF single-wheel vehicle model is powerful and persuasive when simulating vehicle dynamic load [18]. Without loss of generality, the 2-DOF single-wheel vehicle model is employed here to analyze DAF. Vehicle system parameters of standard truck used in this paper can be seen from Table 1 [19].

According to the coordinate system shown in Figure 1, it is supposed that the vertically downward direction is positive, and the unknown displacement vector can be represented as $U=\left[-x_{\mathrm{s}},-x_{\mathrm{t}}\right]^{T}$. Vehicle random dynamic load can be calculated by the following equation:

$$
M \ddot{U}+C \dot{U}+K U=\bar{F}
$$


TABLE 1: Vehicle system parameters.

\begin{tabular}{lc}
\hline Parameter & Value \\
\hline$m_{\mathrm{s}}(\mathrm{kg})$ & 9000 \\
$m_{\mathrm{t}}(\mathrm{kg})$ & 1000 \\
$k_{\mathrm{s}}\left(\mathrm{N} \cdot \mathrm{m}^{-1}\right)$ & $480 \times 10^{3}$ \\
$c_{\mathrm{s}}\left(\mathrm{N} \cdot \mathrm{s} \cdot \mathrm{m}^{-1}\right)$ & $14 \times 10^{3}$ \\
$k_{\mathrm{t}}\left(\mathrm{N} \cdot \mathrm{m}^{-1}\right)$ & $1900 \times 10^{3}$ \\
$c_{\mathrm{t}}\left(\mathrm{N} \cdot \mathrm{s} \cdot \mathrm{m}^{-1}\right)$ & $3 \times 10^{3}$ \\
\hline
\end{tabular}

where $M, U, K$ are the mass matrix, damping matrix, and stiffness matrix of the vehicle model, respectively, and $\mathbf{F}$ is the vertical load of vehicle applied on the bridge deck. Bridges and vehicles are connected by the interaction of tire and deck pavements. The force vector $\mathbf{F}$ can be solved by the following equation:

$$
\mathbf{F}=k_{i} \Delta_{i}+c_{i} \dot{\Delta}_{i}
$$

where $k_{i}$ and $c_{i}$ the stiffness and damping of the $i$ th tire and $\Delta_{i}$ is the vertical contact displacement between the $i$ th tire and pavement surface,

$$
\Delta_{i}=u_{i}-\left(-r_{i}\right)
$$

where $u_{i}$ is the vertical displacement of the $i$ th tire measured from the equilibrium position and $r_{i}$ is the shape function of pavement roughness $x_{\mathrm{g}}$.

\section{Generation of Deck Pavement Roughness}

Erratic fluctuation and pit caused by local damages of pavement are called pavement roughness, which is widely evaluated by International Roughness Index (IRI). According to Paterson's research, there are six different pavement roughness degrees, where the IRI of theoretical smooth longitudinal profile is 1 ; the IRI of moderate roughness is about 6 , and the IRI of highly rough surfaces is 10 [20]. IRI is a dimensionless number which is customarily described by $\mathrm{m} / \mathrm{km}$. In China, deck pavement smoothness is often evaluated by the bump accumulated value BI or variance. Both of the two indexes have good linear correlation with IRI. To simulate a pavement roughness excitation, there are four existing simulated methods for the time-domain model: white noise filtration method, superposition of harmonic (namely, trigonometric series superposition method), AR (autoregression), and AMAR method based on the discrete time sequence and discrete sampling by PSD [21]. In this paper, superposition of the harmonic method is chosen because the algorithmic mechanism is clear, without too much consideration of the discretization degree of the model, and the resulting sample results are continuous. Denote that $G_{\mathrm{d}}(\omega)$ is the pavement surface power spectral density expressed in angular frequency, and $x_{\mathrm{g}}$ is the stochastic response of deck pavements, which can be expressed as follows:

$$
x_{\mathrm{g}}=\sum_{k=1}^{M} A_{k} \cos \left(\omega_{k} t+\phi_{k}\right) \text {, }
$$

where $M$ is a positive integral and $\phi_{k}$ is a random variable distributed in $[0,2 \pi]$. By substituting $\omega=2 \pi v n$, (4) can be converted to the frequency domain:

$$
x_{\mathrm{g}}=\sum_{k=1}^{M} \sqrt{3.26 K_{0} \Delta n} \frac{n_{0}}{n_{k}} \cos \left(2 \pi v n_{k} t+\phi_{k}\right) \text {, }
$$

where $\Delta n=\left(n_{m}-n_{1}\right) / M, n_{m}=2$, and $n_{1}=0.1$ and $v$ is the velocity of vehicle. It will be more efficient to use fast Fourier transform (FFT) when simulation [22, 23]. Take $M=400$, $n=1, v=20 \mathrm{~m} / \mathrm{s}$, when IRI $=2$; the stochastic response of deck pavement $x_{\mathrm{g}}$ is simulated as shown in Figure 4 .

After getting $x_{\mathrm{g}}$, the dynamics differential equation of the 2 -DOF vehicle vibration model in Figure 1 can be expressed as follows:

$$
\begin{aligned}
& m_{\mathrm{s}} \ddot{x}_{\mathrm{s}}=-k_{\mathrm{s}}\left(x_{\mathrm{s}}-x_{\mathrm{t}}\right)-c_{\mathrm{s}}\left(\ddot{x}_{\mathrm{s}}-\ddot{x}_{\mathrm{t}}\right), \\
& m_{\mathrm{t}} \ddot{x}_{\mathrm{t}}=k_{\mathrm{s}}\left(x_{\mathrm{s}}-x_{\mathrm{t}}\right)+c_{\mathrm{s}}\left(\ddot{x}_{\mathrm{s}}-\ddot{x}_{\mathrm{t}}\right)-k_{\mathrm{t}}\left(x_{\mathrm{t}}-x_{\mathrm{g}}\right)-c_{\mathrm{t}}\left(\ddot{x}_{\mathrm{s}}-\ddot{x}_{\mathrm{g}}\right),
\end{aligned}
$$

where $x_{\mathrm{s}}$ and $x_{\mathrm{t}}$ are the vertical vibration displacement of suspension and tire, respectively, and $x_{\mathrm{g}}$ is the pavement surface roughness excitation displacement. $F_{\mathrm{t}}$ is the random load of vehicle applied on deck pavement,

$$
F_{\mathrm{t}}=F_{\mathrm{d}}+G
$$

where $F_{\mathrm{d}}$ is the additional dynamic load of tire and $G=\left(m_{\mathrm{s}}+m_{\mathrm{t}}\right) g$, then

$$
F_{\mathrm{d}}=k_{\mathrm{t}}\left(x_{\mathrm{t}}-x_{\mathrm{g}}\right)+c_{\mathrm{t}}\left(\dot{x}_{\mathrm{t}}-\dot{x}_{\mathrm{g}}\right) .
$$

$F_{\mathrm{d}}$ is shown in Figure 5, and the DAF $\mu=F_{\mathrm{d}} / G$.

\section{The Relationship between $\mu, v$, and IRI}

To investigate the effect of $v$ and IRI on $\mu$, let IRI be 0.5 (nearly absolutely smooth), 2 (smoothness is well), 4 (slightly rough), 6 (medium rough), 8 (highly rough), and 10 (very poor condition), the response curves of $\mu$ for different IRIs when $v$ varies from $5 \mathrm{~m} / \mathrm{s}$ to $35 \mathrm{~m} / \mathrm{s}$ are shown in Figure 6 .

When IRI $=0.5$, it can be seen from Figure $6(\mathrm{a})$ that with velocity increasing, $\mu$ increases gradually at first and then decreases. When $v=20 \mathrm{~m} / \mathrm{s}, \mu$ reaches its maximum value and increases more than doubling compared to $v=5 \mathrm{~m} / \mathrm{s}$. Therefore, if deck pavement is very well, the additional dynamic load of vehicle is not ever-increasing but diminishing when $v>20 \mathrm{~m} / \mathrm{s}$ with speedup; If IRI $=2$, the variation curve of $\mu$ increases rapidly at first from $v=5 \mathrm{~m} / \mathrm{s}$ to $v=10 \mathrm{~m} / \mathrm{s}$ and gets its peak value at $v=10 \mathrm{~m} / \mathrm{s}$. Then with speedup, $\mu$ began to decrease quickly till $v=15 \mathrm{~m} / \mathrm{s}$, and as $v$ exceeds $15 \mathrm{~m} / \mathrm{s}$, the curve increases as a whole. As IRI $=4,6$, 8,10 , respectively, we can see some common characteristics clearly from Figures 6(c) and 6(f) that there are two obvious summits and a trough of the line and the maximum will be achieved when $v=10 \mathrm{~m} / \mathrm{s}$ and minimum when $v=15 \mathrm{~m} / \mathrm{s}$. These manners could be explained from the definition equation of additional dynamic load $F_{\mathrm{d}}$, which is determined by the displacement $x_{\mathrm{g}}$ and its derivate $\dot{x}_{\mathrm{g}}$. Because $x_{\mathrm{g}}$ and $\dot{x}_{\mathrm{g}}$ are the trigonometric functions of velocity $v$ which can be seen from (5), $\mu(v)$ must superposed by several trigonometric functions. All of these explains why $\mu$ increases and decreases alternately with the variation of $v$. In fact, the DAF $\mu$ fluctuates continuously as $v$ changes. 


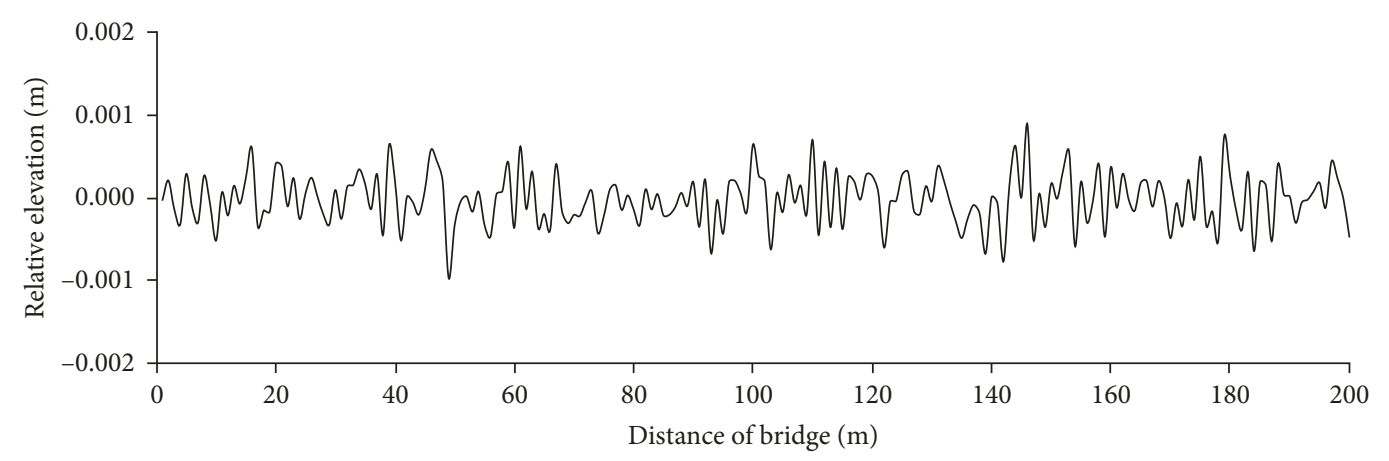

FIGURE 4: Pavement simulation with roughness when IRI $=2$.

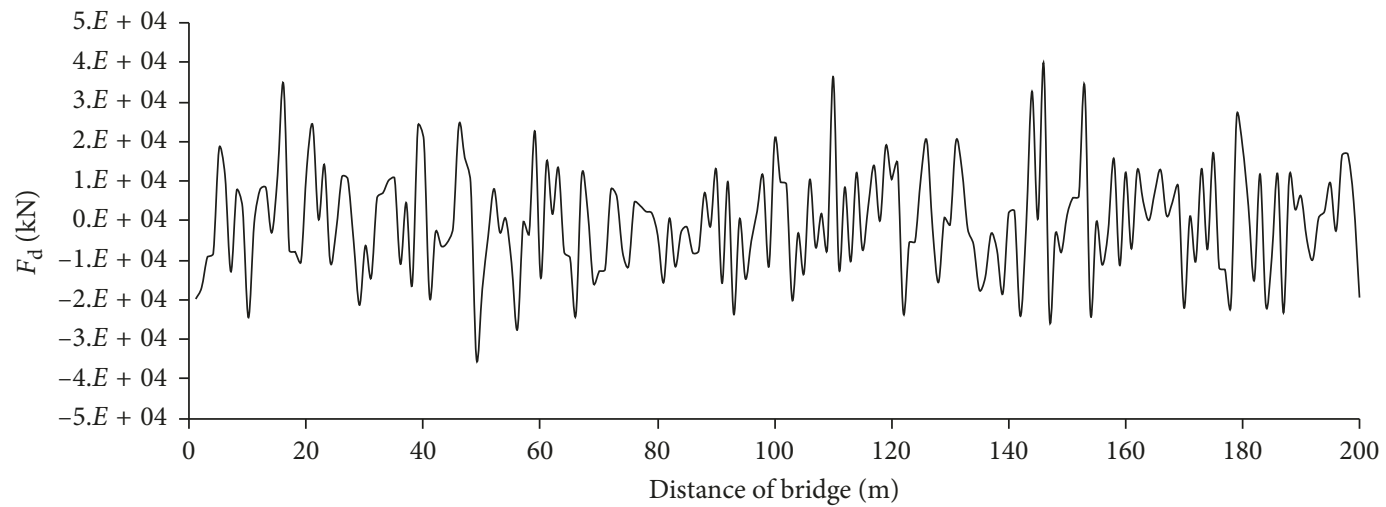

FIgure 5: Additional dynamic load of vehicle when IRI $=2$.

Based on analysis above, we can conclude that deck pavement roughness greatly affects the dynamic amplification factor, and under the same IRI, the response curve of $\mu$ exists two obvious summits and a trough of the line and differs from that of ideal smooth pavement which first increases and then decreases. When a heavy vehicle running over the bridge whose smoothness is general or poor, the velocity should be better controlled at $15 \mathrm{~m} / \mathrm{s}$, and once the speed reaches $10 \mathrm{~m} / \mathrm{s}$ or $25 \mathrm{~m} / \mathrm{s}$, the impact effect caused by vehicle vibration would significantly influence the driving comfortableness and service life of deck pavement.

If the velocity is constant and IRI is a variation, it can be seen from Figure 7 that when IRI $<4$, the influence of $v$ on $\mu$ for different $v$ is similar, while once IRI $>4$, the character of response curves for different $v$ differs significantly.

\section{The Effect of Deck Pavement Structure on Pavement Stress}

In existing researches, many literatures study the influence of deck pavement thickness on control stresses only under dead load or moving constant load of vehicle, regardless of the function of additional dynamic load caused by deck pavement roughness. In this section, the influence of different types of load on control stress response will be considered in order to further study the influence law of pavement structure on control stress.
5.1. Thickness of Asphalt Pavement. Taking a simple supported bridge with a span of $20 \mathrm{~m}$ and width of $12.6 \mathrm{~m}$ as an example, the section of the BDP is shown in Figure 8. Then, the response of control stresses under different load when asphalt layer thickness changes from $4 \mathrm{~cm}$ to $16 \mathrm{~cm}$ is investigated by software ANSYS. In this study, $\sigma_{z}$ and $\sigma_{x}$ represent the longitudinal and transverse tensile stress of asphalt pavement (AP), respectively; $\sigma_{1}$ represents the first principle stress of the AP layer (tensile); $\tau_{x y}$ represents the transverse shear stress in the contact surface between the AP and WP layers; $\tau_{y z}$ represents the longitudinal shear stress in the contact surface between the AP and WP layers; and $\sigma_{y}$ represents normal tensile stress in the contact surface. These six stresses are collectively referred to as the control stress of the BDP, while $\tau_{x y}, \tau_{y z}$, and $\sigma_{y}$ are interlayer contact stresses.

The four response curves in figures below, respectively, stand for vehicle dead load fixed in middle span (dead load), moving load without considering additional dynamic load caused by roughness (moving constant load), vehicle random dynamic load when IRI $=4$ and $v=10 \mathrm{~m} / \mathrm{s} \quad(I=4$, $v=10)$, and vehicle random dynamic load when IRI $=4$ and $v=20 \mathrm{~m} / \mathrm{s}(I=4, v=20)$.

It can be seen from Figures 9-14 that (1) the response regularities of extreme values of $\sigma_{x}$ and $\sigma_{1}$ are similar, and both increase linearly with asphalt pavement thickness increasing. Furthermore, the response of random dynamic load is greater than that of dead load and moving constant load. The maximum value of stress response is the curve " $I=4, v=20$ " and the response of dead load is no different 


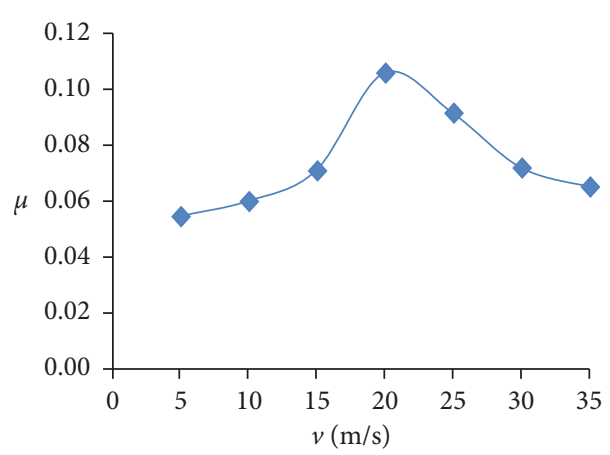

(a)

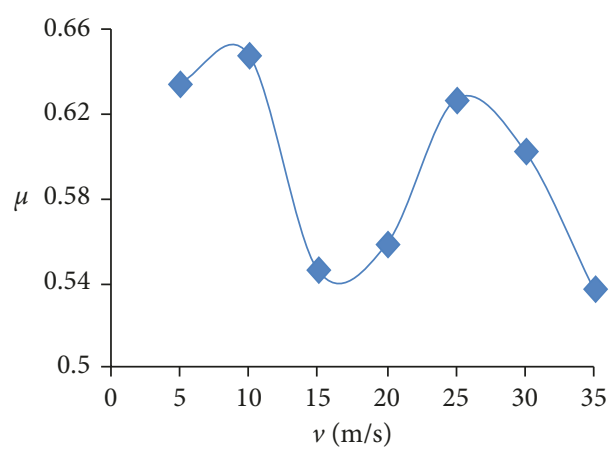

(c)

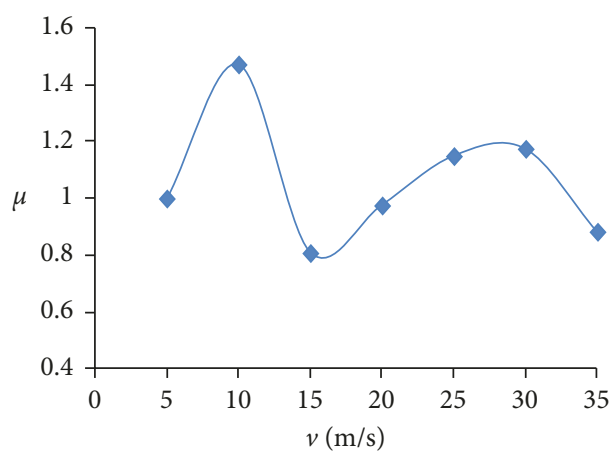

(e)

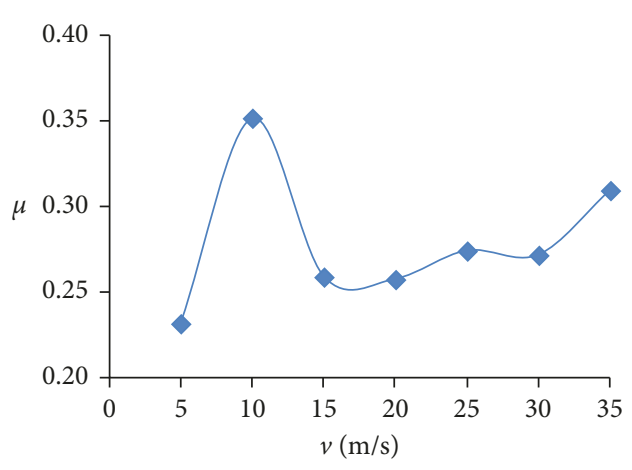

(b)

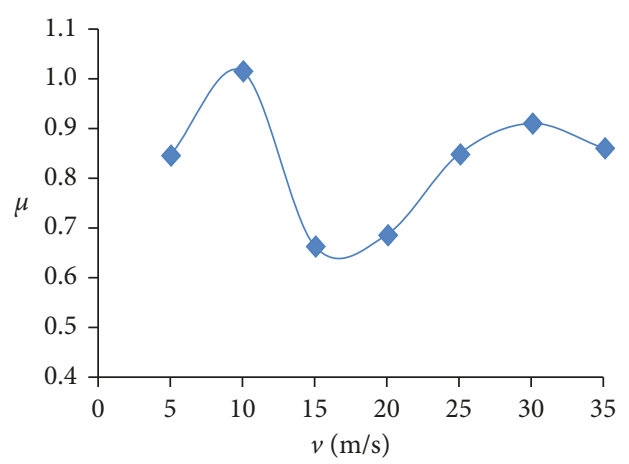

(d)

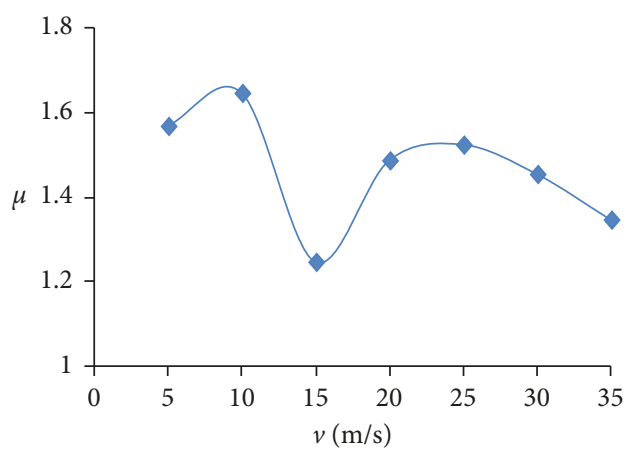

(f)

Figure 6: The relationship between $v$ and $\mu$. (a) IRI $=0.5$, (b) $I R I=2,(c) I R I=4$, (d) IRI =6, (e) IRI = 8, and (f) IRI = 10 .

than moving constant load; (2) the response curve of $\tau_{x y}$ is escalating first and then descending. The maximum value will be achieved when the thickness is $6 \mathrm{~cm}$. The effect of dead load and moving constant load on $\tau_{x y}$ is similar and less than random dynamic load; (3) the extreme response of $\sigma_{y}$ and $\sigma_{z}$ is similar under different loads: descending rapidly with thickness increase and later escalating, the minimum value is achieved when thickness is $6 \mathrm{~cm}$; (4) the variation regularity of the response curve of $\tau_{y z}$ is relatively complicate, and the minimum value will be achieved when thickness is $10 \mathrm{~cm}$.

Through comprehensive analysis we can conclude that if asphalt pavement is too thin, the extreme response of $\sigma_{y}$ and $\sigma_{z}$ would be too large; increase thickness properly will contribute to diminish the response, but asphalt layer should not be too thick because it will be bad for the response of $\sigma_{x}$ and $\sigma_{1}$; under the effect of stochastic dynamic load, $\tau_{y z}$ and $\tau_{x y}$ only reduce by $7.5 \%$ and $6.6 \%$, respectively, when thickness increases from $10 \mathrm{~cm}$ to $16 \mathrm{~cm}$. Besides, the increasing of thickness could not only augment the self-weight of the bridge but lead to unnecessary waste economically. So, for the composite deck pavement structure, the thickness of asphalt should be better controlled for about $10 \mathrm{~cm}$.

5.2. Design Principle. Concrete cushion is paved above girder to protect and level the bridge deck. To analyze its effect on pavement stress, suppose that the thickness of the cushion layer changes within the range of $3 \mathrm{~cm}$ to $10 \mathrm{~cm}$.

Through analysis we can find that overall increasing cushion thickness can help to decrease pavement stresses to some extent; the extreme responses of $\sigma_{y}, \sigma_{x}$ and $\sigma_{1}$ all descend linearly under different loads while the stress response of dead load and moving constant load is less than 


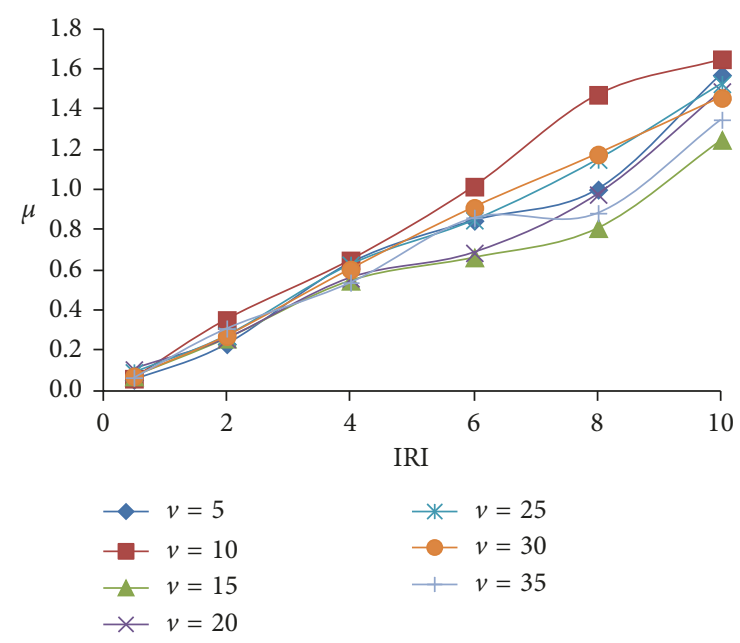

Figure 7: The relationship between IRI and $\mu$.

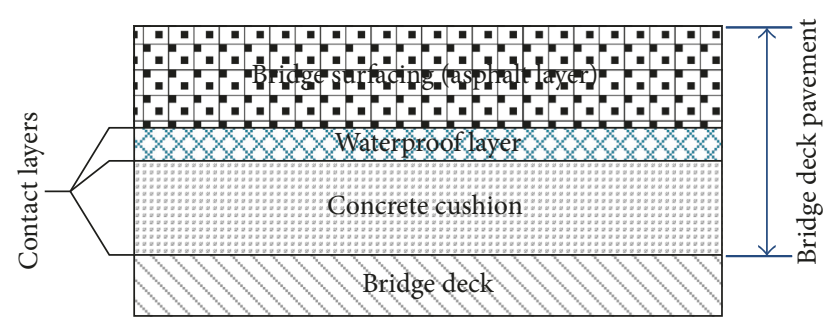

Figure 8: The section of bridge deck pavement.

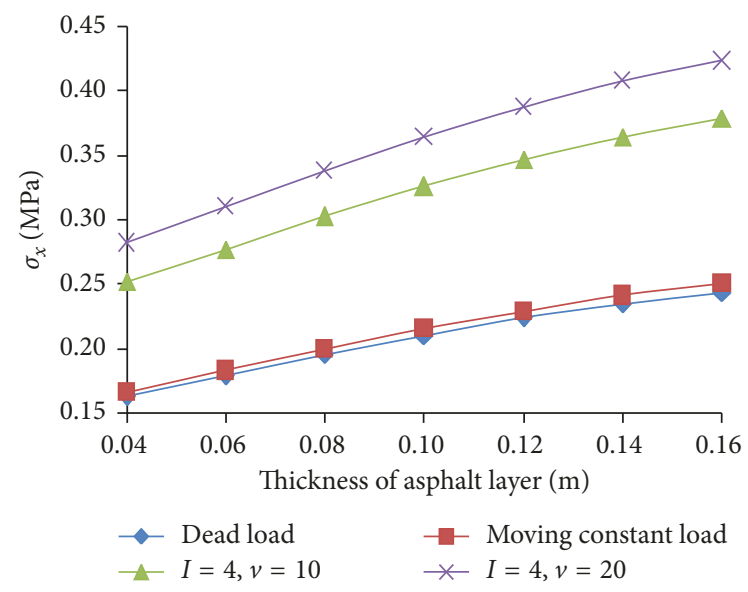

Figure 9: Response curve of $\sigma_{x}$.

the random dynamic load; response curves of $\tau_{x y}, \tau_{y z}$, and $\sigma_{z}$ are reducing greatly when cushion thickness increases from $3 \mathrm{~cm}$ to $4 \mathrm{~cm}$ and then descends slowly as thickness continues increasing. It follows that the response trend of each stress is relatively similar under action of different loads. The relative reduction of most stress extreme values is biggest when cushion thickness increases from $3 \mathrm{~cm}$ to $4 \mathrm{~cm}$. Besides, allowing for the effect of self-weight of bridge caused by increasing cushion layer thickness, the thickness of the cushion layer should be better controlled for about $4 \mathrm{~cm}$.

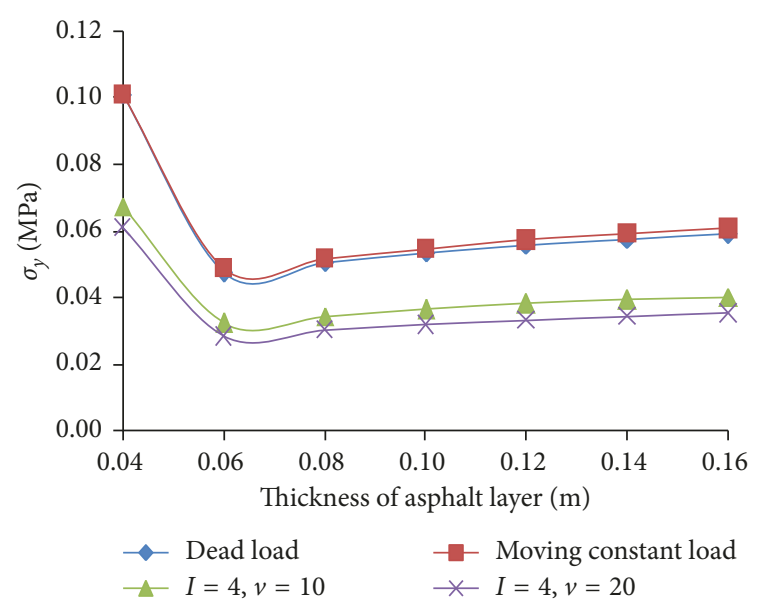

Figure 10: Response curve of $\sigma_{y}$.

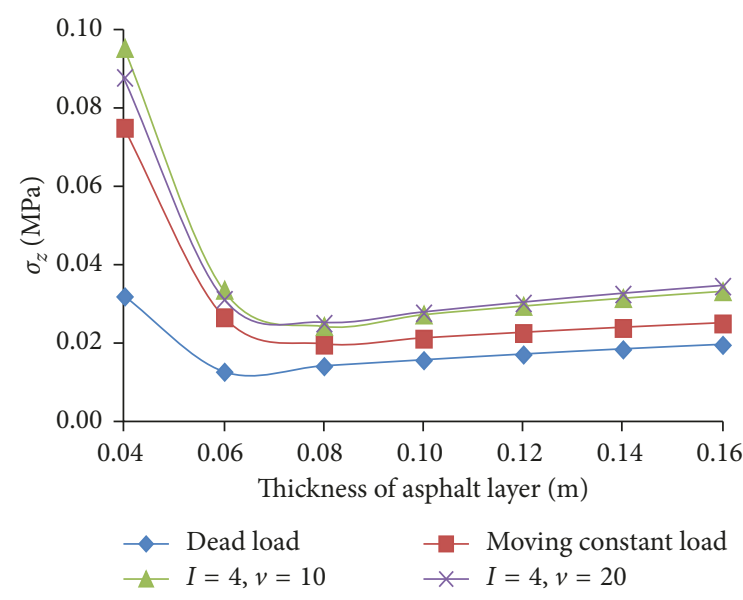

Figure 11: Response curve of $\sigma_{z}$.

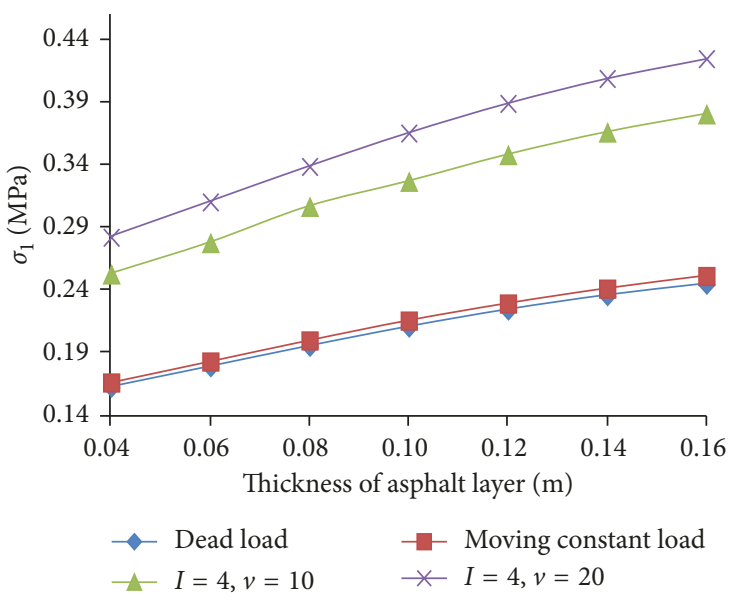

FiguRE 12: Response curve of $\sigma_{1}$

5.3. Elastic Modulus of Deck Pavement Materials. The elastic modulus of common asphalt materials ranges from $1000 \mathrm{MPa}$ to $2000 \mathrm{MPa}$; through analysis we can find that the extreme values of control stresses all increase in different degrees; the extreme response curves of $\sigma_{x}, \sigma_{1}, \tau_{x y}$, and $\tau_{y z}$ 


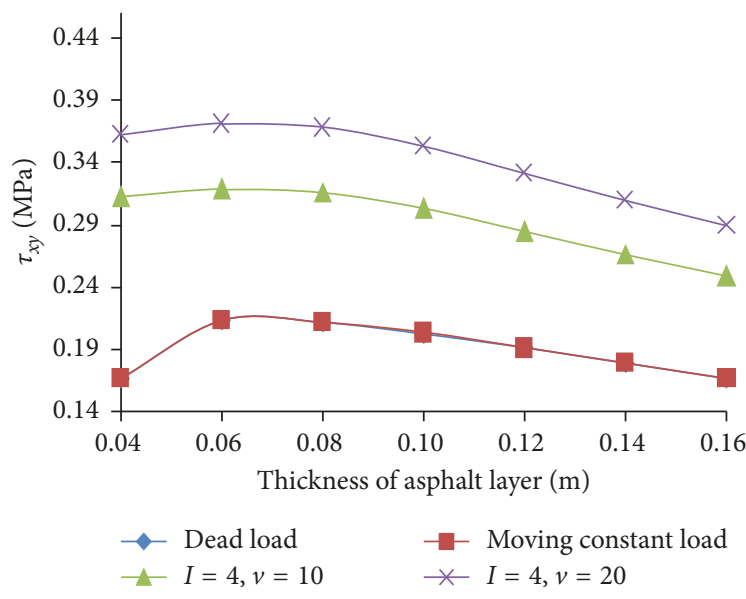

FIGURE 13: Response curve of $\tau_{x y}$.

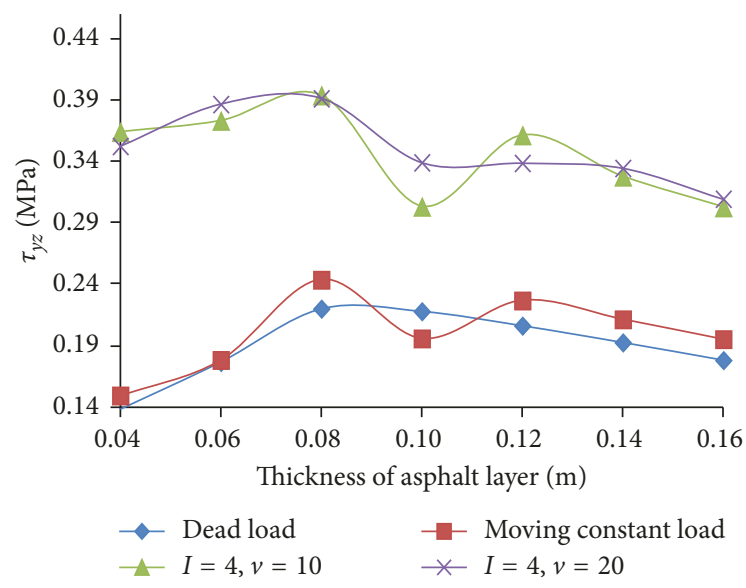

FIGURE 14: Response curve of $\tau_{y z}$.

have similar variation trend, and the maximum response is caused by the random dynamic load; the relative variation of extreme values of each stress caused by increment of elastic modulus is very close.

Enhancing elastic modulus of the cushion layer can diminish pavement stress response to some extent, but the relative reduction of each stress is less than $2 \%$ for every $2 \mathrm{GPa}$, and the elastic modulus of cushion increases. It is because that the local effect on the deck pavement layer is obvious under vehicle loads, and the variation of elastic modulus of cushion can seldom improve the stress state of the upper layer.

\section{Conclusion and Discussion}

Existing researches of vehicle-bridge vibration only consider the interaction of vehicle and bridge and seldom take deck pavement into consideration. Meanwhile, the overloaded vehicles' additional dynamic load caused by pavement roughness degree is also neglected by designers during bridge's operating process. So, accurately analyzing the dynamic amplification factor caused by IRI and $v$ is meaningful and necessary. In first part, this study investigated the relationship between $\mu$ with IRI and $v$, while the second part analyzed the influence of different types of load on control stress response and further studied the influence regularity of pavement structure on control stress so as to study the influence factor and change law of dynamic load deeply and to further guide the design of pavement structure safely and reliably. The main results are shown as follows:

(1) The roughness of BDP greatly affects the dynamic amplification factor, and under the same IRI, the response curve of $\mu$ exists between two obvious summits and a trough of the line and differs from that of ideal smooth pavement which first increases and then decreases. When a heavy vehicle running over the bridge whose smoothness is general or poor, the velocity should be better controlled at $15 \mathrm{~m} / \mathrm{s}$, and once the speed reaches $10 \mathrm{~m} / \mathrm{s}$ or $25 \mathrm{~m} / \mathrm{s}$, the impact effect caused by vehicle vibration would significantly influence the driving comfortableness and service life of deck pavement

(2) The increasing of thickness could not only augment the self-weight of bridge but lead to unnecessary waste economically. The thickness of asphalt should be better controlled about $10 \mathrm{~cm}$.

(3) Increasing cushion thickness can help to decrease pavement stresses to some extent, and allowing for the effect of self-weight of bridge caused by increasing the cushion layer thickness, the thickness of the cushion layer should be better controlled about $4 \mathrm{~cm}$.

(4) Enhancing elastic modulus of the cushion layer can diminish pavement stress response to some extent, but the relative reduction of each stress is less than $2 \%$ for every $2 \mathrm{GPa}$, and the elastic modulus of cushion increases. Thus, it is uneconomical to decrease pavement stress by using high-grade concrete cushion.

\section{Conflicts of Interest}

The authors declare that they have no conflicts of interest.

\section{Acknowledgments}

This work is supported by the State High-Tech Research and Development Plans (863) (Grant no. 2014AA110402); Shanghai Urban Construction Design Research Institute Project "Bridge Safe Operation Big Data Acquisition Technology and Structure Monitoring System Research"; the Ministry of Transport Construction Science and Technology Project "Medium-Small Span Bridge Structure Network Level Safety Monitoring and Evaluation"; and the Project of National Key Technology R\&D Program in the 12th FiveYear Plan of China (Grant no. 2012BAJ11B01).

\section{References}

[1] Y. J. Zhou, J. Z. Cai, X. W. Shi, and Y. Zhao, "Computing method of bridge impact factor based on weighted method," Journal of Traffic and Transportation Engineering, vol. 13, no. 4, pp. 29-36, 2013. 
[2] X. F. Yin and Z. Fang, "Random vibration analysis of vehiclepavement-bridge system under vehicle braking," Chinese Journal of Computational Mechanics, vol. 27, no. 5, pp. 936-941, 2010.

[3] S. R. Chen and C. S. Cai, "Accident assessment of vehicles on long-span bridges in windy environments," Journal of Wind Engineering and Industrial Aerodynamics, vol. 92, no. 12, pp. 991-1024, 2004.

[4] P. W. Hao, S. H. He, Y. Song et al., "Vehicle-bridge coupled vibration and its influencing factors of simple beam," Journal of Chang'an University, vol. 33, no. 1, pp. 59-66, 2013.

[5] E. S. Hwang and A. S. Nowak, "Simulation of dynamic load for bridges," Journal of Structural Engineering, vol. 117, no. 5, pp. 1413-1434, 1991.

[6] S. H. Ju and H. T. Lin, "A finite element model of vehiclebridge interaction considering braking and acceleration," Journal of Sound and Vibration, vol. 303, no. 1-2, pp. 46-57, 2007.

[7] L. Deng and C. S. Cai, "Development of dynamic impact factor for performance evaluation of existing multi-girder concrete bridges," Engineering Structures, vol. 32, no. 1, pp. 21-31, 2010.

[8] C. C. Caprani, "Lifetime highway bridge traffic load effect from a combination of traffic states allowing for dynamic amplification," Journal of Bridge Engineering, vol. 18, no. 9, pp. 901-909, 2013.

[9] L. Deng, Y. Yu, Q. Zou, and C. S. Cai, "State-of-the-art review of dynamic impact factors of highway bridges," Journal of Bridge Engineering, vol. 20, no. 5, p. 04014080, 2014.

[10] CCCC Highway Consultants Co., Ltd., JTG D60-2004 General Code for Design of Highway Bridges and Culverts, China Communications Press, Beijing, China, 2004.

[11] F. Han, H. Wang, and D.-H. Dan, "Dynamic response of a bridge deck pavement," Proceedings of the Institution of Civil Engineers-Transport, pp. 1-12, 2017.

[12] X. Peng, X. F. Yin, and Z. Fang, "The coupled vibration analysis of elastically supported bridge with uneven surface and speed-varying vehicle," Journal of Vibration and Shock, vol. 26, no. 5, pp. 19-23, 2007.

[13] X. Peng, X. F. Yin, and Z. Fang, "Vibration and TMD control of coupled system of girder bridge and vehicle with variable speeds," Journal of Hunan University, vol. 33, no. 5, pp. 61-66, 2006.

[14] L. Sun and X. J. Deng, "Transient response of bridge to traveling random vehicle loads," Journal of Vibration and Shock, vol. 16, no. 1, pp. 142-145, 1997.

[15] Y. Liu and Z. D. Qian, "Review of road roughness and vehicle vibration model," Journal of Highway and Transportation Research and Development, vol. 25, no. 1, pp. 51-57, 2008.

[16] S. S. Law and X. Q. Zhu, "Dynamic behavior of damaged concrete structure under moving vehicle loads," Engineering Structure, vol. 24, no. 4, pp. 1279-1293, 2004.

[17] H. L. Zhang and C. S. Hu, "A study on allowable differential slope of approach slab with five-degree-freedom vehicle model," China Civil Engineering Journal, vol. 38, no. 6, pp. 125-130, 2005.

[18] L. Sun and T. Kennedy, "Spectral analysis and parametric study of stochastic pavement load," Journal of Engineering Mechanics, vol. 128, no. 3, pp. 318-327, 2002.

[19] J. H. Li, J. He, and X. H. Li, "Dynamic response of pavement under vehicle random load and moving constant load," Journal of Chang'an University, vol. 35, no. 2, pp. 38-45, 2015.

[20] W. D. Paterson and T. Watanatada, "Relationships between vehicle speed, ride quality, and road roughness," in Measuring
Road Roughness and its Effects on User Cost and Comfort, T. D. Gillespie and M. Sayers, Eds., pp. 89-110, ASTM International, West Conshohocken, PA, USA, 1985.

[21] Y. L. Zhang and Y. F. Zhong, "Time domain model of road undulation excitation to vehicles," Transaction of the Chinese Society of Agricultural Machinery, vol. 35, no. 2, pp. 9-12, 2004.

[22] Y. Cheng and Y. K. Cheung, "Effects of random road surface roughness and long-term deflection of prestressed concrete girder and cable-stayed bridges on impact due to moving vehicles," Computers and Mechanics, vol. 79, pp. 853-872, 2001.

[23] W. Schiehlen and B. Hu, "Spectral simulation and shock absorber identification," International Journal of Non-Linear Mechanics, vol. 38, no. 2, pp. 161-171, 2003. 


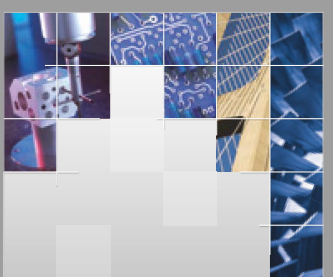

\section{Enfincering}
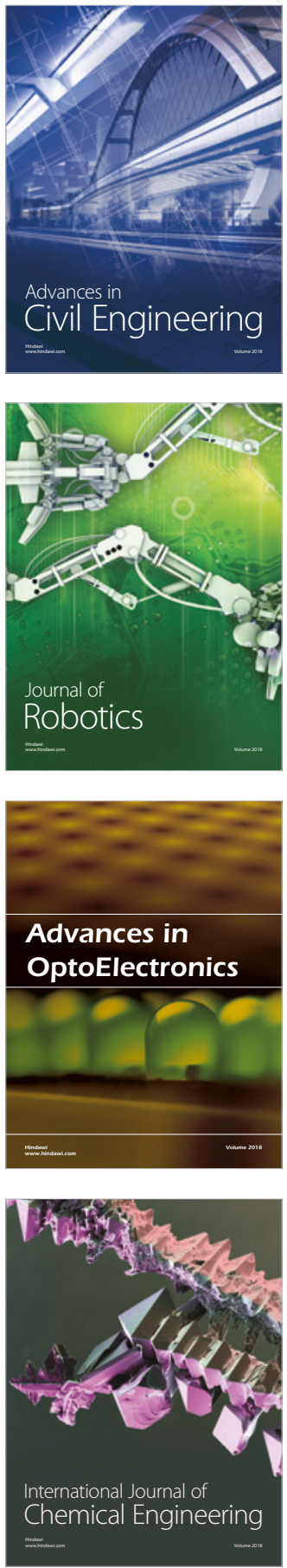

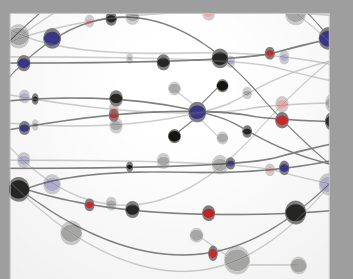

\section{Rotating \\ Machinery}

The Scientific World Journal

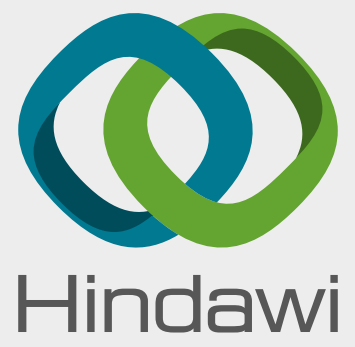

Submit your manuscripts at

www.hindawi.com
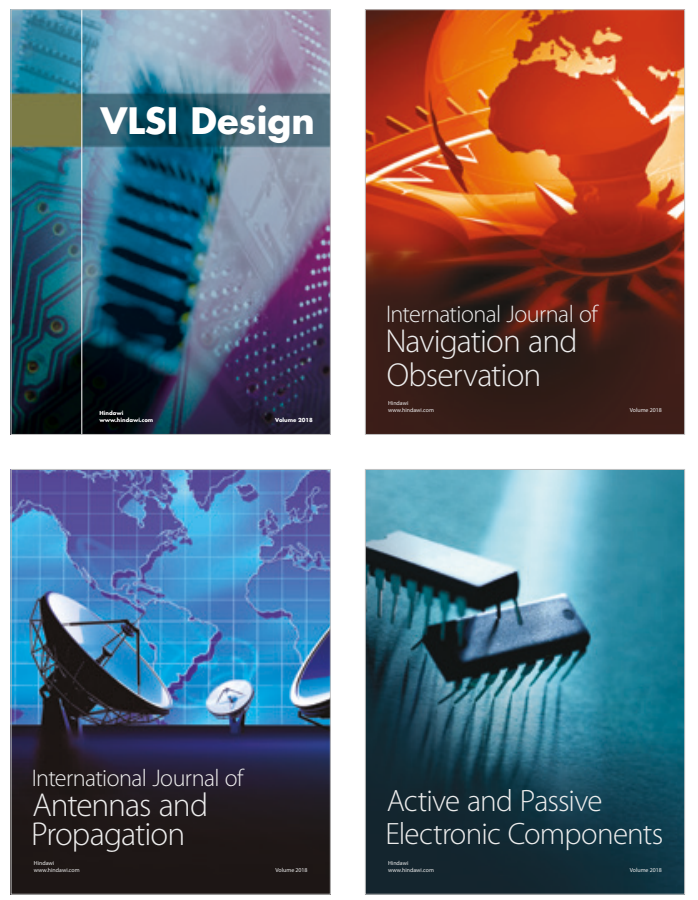
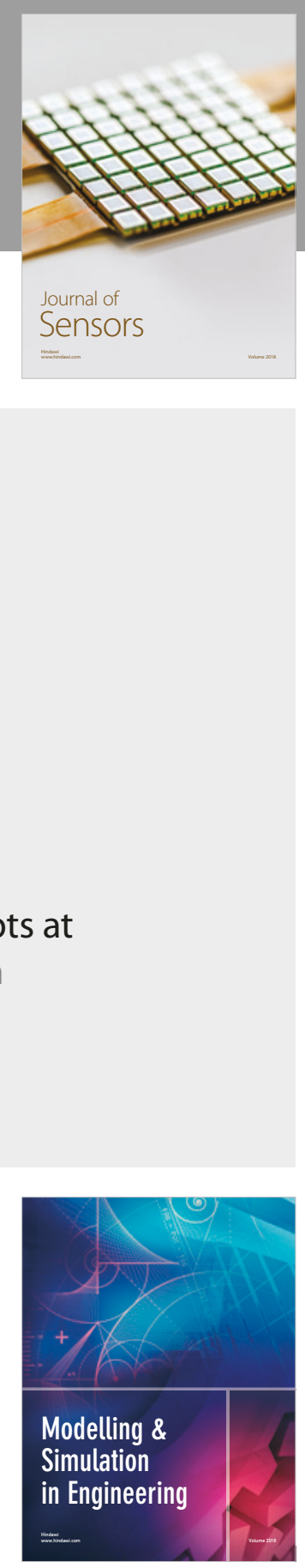

\section{Advances \\ Multimedia}
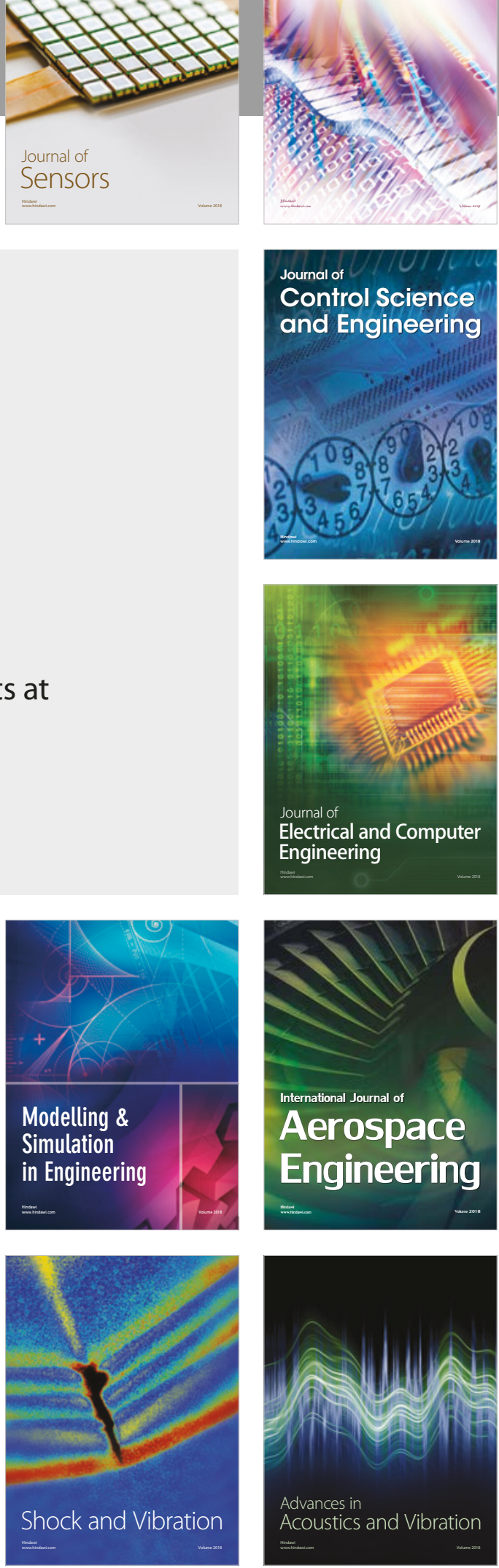